OPEN ACCESS

Edited by:

Feng Chen,

Augusta University, United States

Reviewed by:

Ana Denicola,

University of the Republic, Uruguay Yeong-Renn Chen,

Northeast Ohio Medical University,

United States

*Correspondence:

Yoshimi Niwano

niwano@m.tohoku.ac.jp

Mika Tada

mika_tada@tohtech.ac.jp

Specialty section

This article was submitted to

Oxidant Physiology

a section of the journal

Frontiers in Physiology

Received: 10 June 2017 Accepted: 07 September 2017 Published: 21 September 2017

Citation:

Niwano Y, Tada M and Tsukada M (2017) Antimicrobial Intervention by Photoirradiation of Grape Pomace

Extracts via Hydroxyl Radical Generation. Front. Physiol. 8:728. doi: 10.3389/fphys.2017.00728

\section{Antimicrobial Intervention by Photoirradiation of Grape Pomace Extracts via Hydroxyl Radical Generation}

\author{
Yoshimi Niwano ${ }^{1 *}$, Mika Tada ${ }^{2 *}$ and Mana Tsukada ${ }^{3}$ \\ ${ }^{1}$ Graduate School of Dentistry, Tohoku University, Sendai, Japan, ${ }^{2}$ Center for General Education, Tohoku Institute of \\ Technology, Sendai, Japan, ${ }^{3}$ HABA Laboratories Inc., Tokyo, Japan
}

The annual production of grape worldwide amounts to almost 70 million tons, and around $80 \%$ is used for winemaking. The two major wastes from winemaking process, pomace and lees account for 20 and $7 \%$ of the grapes, respectively. They have been expected as a valuable resource to be recycled because they are rich in polyphenols. Polyphenols possess prooxidatve activity as well as antioxidative one just like a two sides of a coin. A typical example of the prooxidative activity is antibacterial activity of catechins. The activity is exerted through oxidation of phenolic hydroxyl moiety coulpled with reduction of dissolved oxygen leading to hydrogen peroxide $\left(\mathrm{H}_{2} \mathrm{O}_{2}\right)$ generation. In addition, once the oxidation of phenolic hydroxyl moiety is augmented by photoirradiation, highly reactive hydroxyl radical $(\cdot \mathrm{OH})$ is generated. Accordingly, there have been several reports showing that photoirardiation of polyphenols exerts bactericidal activity via $\cdot \mathrm{OH}$ generation. This review focuses mainly on antimicrobial intervention by photoirradiation of grape pomace extract in relation to $\cdot \mathrm{OH}$ generation analyzed by an electron spin resonance-spin trapping method.

Keywords: grape pomace, photooxidation of polyphenol, hydroxyl radical, electron spin resonance, spin trapping

\section{PROOXIDATIVE PROPERTY OF POLYPHENOLS}

Polyphenolic compounds naturally occurring in fruits, nuts, vegetables and flowers are noteworthy for their antioxidative activity (Kondo et al., 1999; Liu et al., 2000; Yilmaz and Toledo, 2004). The phenolic hydroxyl moiety in their structures functions as a hydrogen (and electron) donor, which enables them to scavenge free radicals effectively (Hanasaki et al., 1994; Heim et al., 2002). Accordingly, polyphenols in terms of their beneficial antioxidative activity have been well studied and applied to health promotion (Ahmad et al., 2000; Williamson and Manach, 2005; Khan and Mukhtar, 2007).

In addition to antioxidative potential of polyphenols, their prooxidative potential has been also studied. One of the typical examples is tea catechin with cupric ion showing a prooxidative activity to DNA cleavage reaction and linoleic acid peroxidation (Hayakawa et al., 1997). More in detail, the catechin probably acts to reduce $\mathrm{Cu}^{2+}$ to $\mathrm{Cu}^{+}$expressed as Equation $\mathrm{i}$. Then the resultant $\mathrm{Cu}^{+}$ produces reactive oxygen species (ROS) attacking the DNA (Equations ii-iv). In the equations, superoxide anion radical is abbreviated as $\cdot \mathrm{O}_{2}^{-}$. Especially, the Eq iv is well known as a Fenton reaction in which transition metal catalyzes hydrogen peroxide $\left(\mathrm{H}_{2} \mathrm{O}_{2}\right)$ to generate highly reactive hydroxyl radical (.OH). 


$$
\begin{aligned}
& \text { catechin }+\mathrm{Cu}^{2+} \rightarrow \text { oxidized catechin }+\mathrm{Cu}^{+} \\
& \mathrm{Cu}^{+}+\mathrm{O}_{2} \rightarrow \mathrm{Cu}^{2+}+\cdot \mathrm{O}_{2}^{-} \\
& 2 \mathrm{Cu}^{+}+\mathrm{O}_{2}+2 \mathrm{H}^{+} \rightarrow 2 \mathrm{Cu}^{2+}+\mathrm{H}_{2} \mathrm{O}_{2} \\
& \mathrm{Cu}^{+}+\mathrm{H}_{2} \mathrm{O}_{2} \rightarrow \mathrm{Cu}^{2+}+\cdot \mathrm{OH}+\mathrm{OH}^{-}
\end{aligned}
$$

Likewise, it was shown that an anticancer action of plant polyphenols is executed by intracellular copper mobilization and ROS generation, which would be a feature of prooxidative properties of polyphenols, leading to cancer cell death (Khan et al., 2014). More in detail, polyphenols including luteolin, apigenin, epigallocatechin-3-gallate, and resveratrol inhibited cell proliferation and induced apoptosis in different cancer cell lines, and such cell death was prevented by cuprous chelator neocuproine and ROS scavengers. Furthermore, normal breast epithelial cells cultured in a medium supplemented with copper could be suffer from such polyphenol-induced growth inhibition. As such, the high concentration of copper in cancer cells would be a crucial factor for the preferential cytotoxicity of several polyphenols with diverse chemical structures toward cancer cells.

The other typical example of prooxidative action of polyphenols is antibacterial activity of catechins. It was reported that catechins (epicatechin, epicatechin gallate, epigallocatechin and epigallocatechin gallate) possess strong bactericidal action due to ROS such as $\mathrm{H}_{2} \mathrm{O}_{2}$ generated through the oxidation of catechins as the active mechanism (Arakawa et al., 2004). Focusing attention on the antibacterial action of catechins, several studies have been conducted. These studies discuss augmented bactericidal action of polyphenols upon photoirradiation (Nakamura et al., 2012, 2013, 2015). To be more precise, photoirradiation of polyphenol aqueous solution led to the generation of $\mathrm{H}_{2} \mathrm{O}_{2}$ that was in turn homolytically cleaved to $\cdot \mathrm{OH}$. The resultant $\cdot \mathrm{OH}$ caused oxidative damage leading to bacterial death. As illustrated in Figure 1, the concept of these studies is that photoirradiation could augment the oxidation of polyphenols, especially the phenolic hydroxyl moieties.

\section{GRAPE POMACE AS A NATURAL RESOURCE OF POLYPHENOLS}

According to FAO (Food and Agriculture Organization) statistics, grape is the largest fruit crop in the world, and the annual production worldwide amounts to almost 70 million tons, and around $80 \%$ is used to make wine. The waste from winemaking process mainly consists of pomace, clarification sediment such as lees, and yeast sediment. Although the generated amount of waste depends on the condition of the grapes at the time of harvest, as well as on what processing methods are used, the levels of waste can be up to $20 \%$ of the harvested mass of the grapes (Russ and Meyer-Pittroff, 2004). Accordingly, such waste materials or byproducts could be a valuable resource to be recycled. Indeed, solid byproducts from white and red wine industry were evaluated as potential sources of antioxidant phytochemicals on the basis of their content in phenolic compounds and in vitro antioxidative activity (Markis et al., 2007). In particular, it is shown that wine industry byproducts, including not only grape seeds but also grape pomace and stems, were very rich sources of antioxidant polyphenols compared with other agri-food solid wastes. Regarding the phenolic compounds contained in winery waste, it was reported that gallic acid, (+)-catechin and (-)epicatechin were the major phenolic compounds in the waste from red winemaking with variety Agiorgitiko, according to a high performance liquid chromatography determination of the extracts obtained under various conditions using different solvents (Lafka et al., 2007). Moreover, hydroxytyrosol, tyrosol, cyanidin glycosides, and various phenolic acids such as caffeic, syringic, vanillic, $\mathrm{p}$-coumaric and o-coumaric acids were identified.

\section{ROS GENERATION FROM PHOTOIRRADIATION OF GRAPE POMACE EXTRACT}

As described above, photoirradiation of polyphenols could exert bactericidal action via generated ROS, especially $\cdot \mathrm{OH}$. In this review, we write up our recent studies showing the photoirradiation-induced bactericidal activity of an aqueous extract from grape pomace from winemaking in relation to ROS generation (Tsukada et al., 2016a,c) The extract was prepared as in the following way. Fruitage (including the peel and seeds) of the white wine grape variety Niagara harvested at Hokkaido in Japan was crushed and pressed to obtain a juice in the vinification process of white wine. Then the remnant of crushed and pressed grapes (grape pomace) was freeze-dried. Three times the volume of pure water (at the ratio of $3 \mathrm{~mL}$ pure water per $1 \mathrm{~g}$ powder) was added to the dried residue powder, and the resultant mixture was agitated at $150 \mathrm{rpm}$ overnight at room temperature. The upper layer was taken and centrifuged at 3,000 rpm for $20 \mathrm{~min}$ to obtain a supernatant. Filtrate through membrane filtration $(\varphi 0.22 \mu \mathrm{m})$ was adjusted to contain designated concentrations of total polyphenols, and was used for the assays. The resultant aqueous extract solution was termed as grape pomace extract (GPE) hereafter.

Qualitative and quantitative analyses of $\cdot \mathrm{OH}$ generated by photoirradiation of GPE were performed using an electron spin resonance (ESR) spin trapping technique with 5,5-dimethyl-1pyrroline $\mathrm{N}$-oxide (DMPO) as a spin trap. In the assay, 300 $\mathrm{mM}$ DMPO was used because it was reported that $300 \mathrm{mM}$ DMPO is optimal to trap $\mu \mathrm{M}$ level of . OH sufficiently (Nakamura et al., 2010). The sample (GPE) was irradiated with a light emitting diode (LED) with a wavelength of $400 \mathrm{~nm}$ for 0,10 , 20 , and $60 \mathrm{~s}$. After irradiation, determination of DMPO-OH (a spin adduct of DMPO and $\cdot \mathrm{OH}$ ) was carried out with 4-hydroxy2,2,6,6-tetramethylpiperidine $N$-oxyl (TEMPOL) as a standard to calculate the concentration of DMPO-OH. To confirm if $\mathrm{DMPO}-\mathrm{OH}$ was derived from the reaction between free $\cdot \mathrm{OH}$ and DMPO, dimethyl sulfoxide (DMSO), a representative $\cdot \mathrm{OH}$ scavenger was added to the reaction mixture, resulting in that DMPO-OH signal decreased, and a signal for DMPO$\mathrm{CH}_{3}$ was observed (Figure 1). The yields of DMPO-OH after 


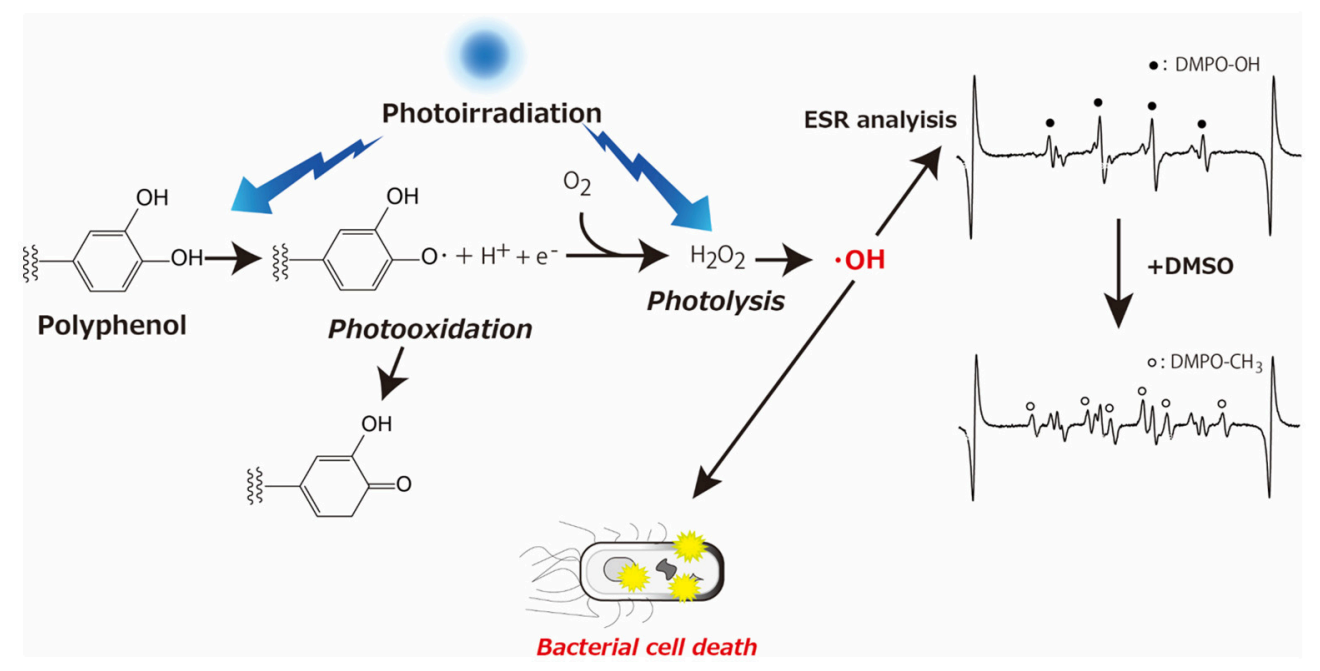

FIGURE 1 | Schematic illustration showing augmented oxidation of phenolic hydroxyl moiety by photoirradiation, which results in hydroxyl radical generation leading to bacterial cell death, with representative ESR spectra obtained by photoirradiation of GPE in the absence or presence of DMSO.

LED-light irradiation of GPE increased linearly with time up to $20 \mathrm{~s}$, and the yield kept similar level after that. When the photoirradiated GPE for 20 min without DMPO was furthered irradiated with LED light for $10 \mathrm{~s}$ in the presence of DMPO, the yield of DMPO-OH was similar to that after $10 \mathrm{~s}$ irradiation of GPE without prior irradiation. That is, even after 20 min photoirradiation, newly added DMPO trapped . $\mathrm{OH}$ indicating that. $\mathrm{OH}$ was generated during photoirradiation for $20 \mathrm{~min}$ or longer. Likewise, further study revealed that . $\mathrm{OH}$ was continuously generated at least up to a couple of hours, even though DMPO-OH level reached a plateau in a short period of time. Besides $\cdot \mathrm{OH}, \mathrm{H}_{2} \mathrm{O}_{2}$ yield determined by a colorimetric method based on the peroxide-mediated oxidation of $\mathrm{Fe}^{2+}$ followed by the reaction of $\mathrm{Fe}^{3+}$ with xylenol orange also increased with irradiation time, confirming the idea that photooxidation of polyphenols contained in GPE resulted in $\mathrm{H}_{2} \mathrm{O}_{2}$ generation and subsequent $\cdot \mathrm{OH}$ formation via homolytic cleavage of $\mathrm{H}_{2} \mathrm{O}_{2}$ (Figure 1). When $\cdot \mathrm{OH}$ yield of photoirradiation of GPE was compared to that of commercially available grape seed extract (GSE, Leucoselect ${ }^{\circledR}$, Indena S.p.A., Milan, Italy) and $(+)$-catechin, GPE was more potent than GSE and $(+)$ catechin.

Regarding polyphenols in GPE, liquid chromatographyelectrospray ionization-mass spectrometry (LC-ESI-MS) analysis showed that polyphenolic compounds including catechin monomers, dimers, trimers, and polyphenolic glucosides were contained (Figure 2).

\section{BACTERICIDAL ACTIVITY OF PHOTOIRRADIATION OF GPE}

Potent bactericidal activity of photoirradiation of GPE was demonstrated against Staphylococcus aureus (Tsukada et al., 2016a,c). When $S$. aureus suspended in GPE was irradiated with LED light at $400 \mathrm{~nm}$ for $20 \mathrm{~min}$, a 5-log or greater reduction in viable bacterial cells was achieved. Once $\cdot \mathrm{OH}$ scavengers were added to the suspension of $S$. aureus, the bactericidal effect of the photoirradiated GPE was prominently attenuated, revealing that the bactericidal activity of photoirradiation of GPE was mainly attributable to $\cdot \mathrm{OH}$. In a study where the effect of wavelengths of light $(365,385,400$, and $465 \mathrm{~nm}$ with irradiance of $715 \mathrm{~mW} / \mathrm{cm}^{2}$ ) was examined, absorption of light by GPE increased as the wavelength was shorter. Accordingly, when the extract was irradiated with the light at the four wavelengths, the shorter the wavelength was, the more $\mathrm{H}_{2} \mathrm{O}_{2}$ was yielded. In addition, it was revealed that $\mathrm{H}_{2} \mathrm{O}_{2}$ yield and bactericidal activity against $S$. aureus under LED-light irradiation increased inversely with the wavelength. Thus, bactericidal activity of photoirradiation of GPE would be augmented by controlling wavelength of light, which could be an advantageous point. Furthermore, when bactericidal activity of photoirradiation of GPE was compared to that of GSE and (+)-catechin, GPE was more potent than GSE and (+)-catechin, which also could give superiority to GPE.

Besides GPE, bactericidal effect of photoirradiation of aqueous extract from wine lees was examined (Tsukada et al., 2016b). Wine lees, also a major waste product of winemaking, was obtained from the same white wine grape variety Niagara as used in GPE, and its aqueous extract (termed as WLE) was similarly prepared as was the case with GPE. Bactericidal activity of photoirradiation of WLE against $S$. aureus was comparable to that of GPE, and also effective against Pseudomonas aeruginosa. However, unlike GPE, -OH yield upon photoirradiation decreased with time. In that sense, we conclude that GPE is a better prooxidative disinfectant than WLE.

A recent study demonstrated that antimicrobial technique based on photooxidation of caffeic acid was highly effective 


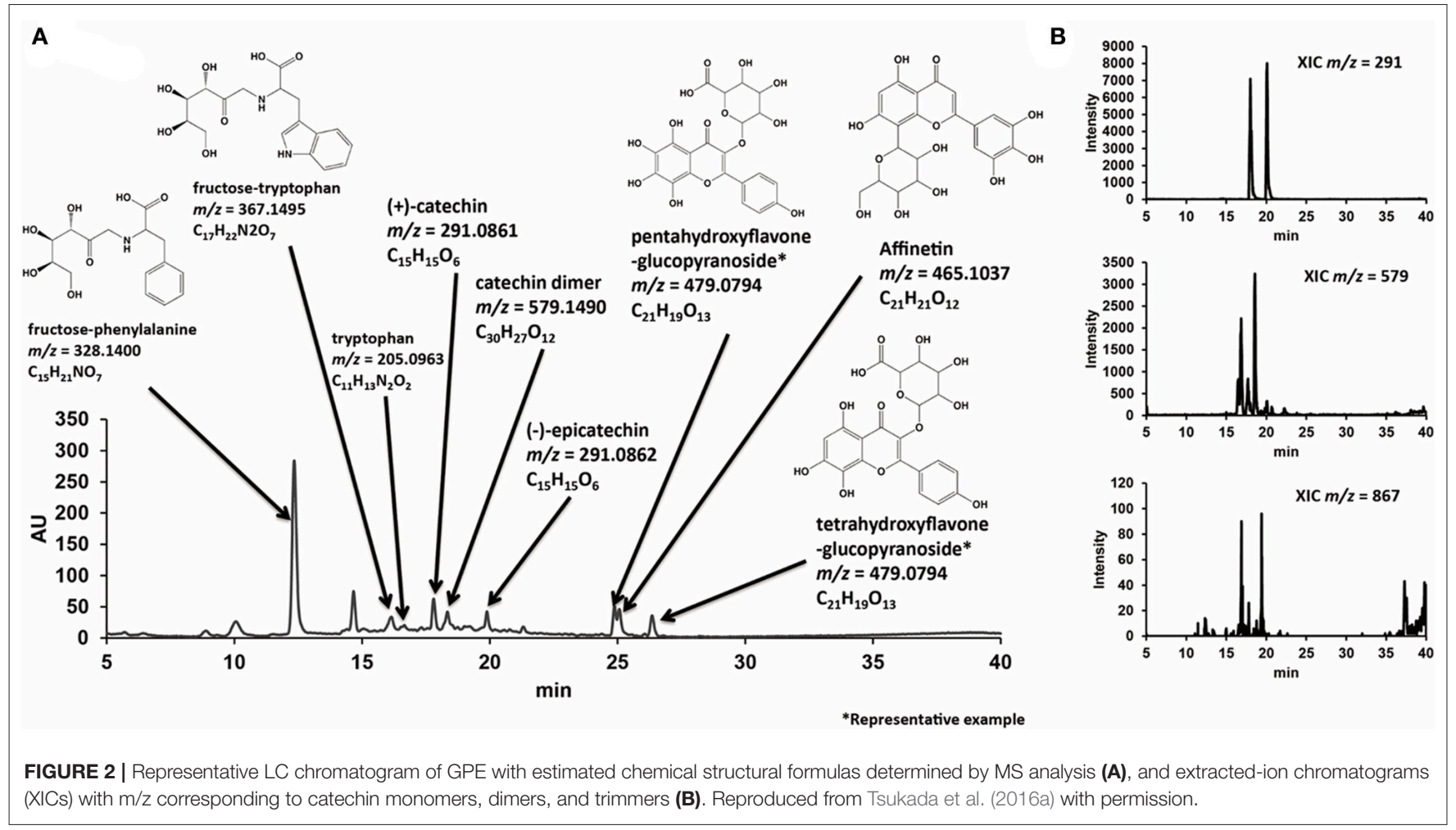

against biofilm-forming Streptococcus mutans, the most common acidogenic bacterial species isolated from human cariogenic dental plaques, in relation to $\cdot \mathrm{OH}$ formation (Nakamura et al., 2017). Therefore, the authors concluded that photoirradiation of caffeic acid has the potential to be applied as an inexpensive antimicrobial therapy to prevent and treat dental caries. As such, one of the possible applications of photoirradiation of GPE would be oral infectious diseases (e.g. dental caries).

\section{CONCLUSION AND FUTURE PERSPECTIVE}

As total amount of grape pomace discharged from winemaking was globally estimated to be approximately 10 million tons, the pomace could be a valuable resource to be recycled. Besides antioxidative resources, one of its beneficial uses as a prooxidant is disinfection with following merits. Since the generation of $\cdot \mathrm{OH}$ from GPE is terminated by cessation of photoirradiation, the prooxidative action does not continue after the disinfection treatment. Even if excessive amount of $\cdot \mathrm{OH}$ is generated, the radicals cannot exist for long time because of its extremely short life time (Roots and Okada, 1975; Pryor, 1986). Therefore, the residual toxicity is practically negligible. Another beneficial point of utilizing $\cdot \mathrm{OH}$ is that the risk of inducing bacterial resistance is quite low because it interacts with several cell structures and different metabolic pathways in microbial cells, probably resulting in a lack of development of bacterial resistance (Ikai et al., 2013). Furthermore, GPE could be edible because it is derived from grape, so that GPE is a safe material to be handled. Accordingly, it is expected that this disinfection technique with photoirradiation of GPE is applicable to wide range fields. Since advanced oxidation process (AOP) can be mentioned as a similar technique, we propose that the technique utilizing photoirradiation of GPE could be applied to ways as in AOP. AOP is well known as a technique that combination of oxidant and ultraviolet (UV) can generate $\mathrm{OH}$. One research group of University of Colorado has extensively studied on AOP application to frontier technologies for water processing and wastewater disinfection such as degradation of organic contaminant and microbial inactivation (Keen et al., 2012, 2016; Keen and Linden, 2013; Lester et al., 2016; Parker et al., 2017). Of their studies, they reported that combination of $\mathrm{H}_{2} \mathrm{O}_{2}$ and low dose UV inactivated adenovirus that is a pathogen resistant to UV disinfection (Bounty et al., 2012). They suggested that $\cdot \mathrm{OH}$ generated by this $\mathrm{AOP}$ damaged proteins that are not UV target, resulting in enhanced inactivation effect of UV. As such we also expect that the disinfection effect of photoirradiation of GPE could be augmented by changing extraction solvent to extract polyphenols more sufficiently, breed variety of grape to be richer in polyphenols, and wavelength of light to generate $\cdot \mathrm{OH}$ more effectively, leading to application to environmental cleanup as reported by the studies on AOP.

The other similar disinfection technique utilizing $\cdot \mathrm{OH}$ is photolysis of $\mathrm{H}_{2} \mathrm{O}_{2}$ originally designed for the treatment 
of periodontitis. Irradiation of blue visible light to $\mathrm{H}_{2} \mathrm{O}_{2}$ generate $\cdot \mathrm{OH}$ that in turn exert not only in vitro bactericidal activity but disinfection effect on a superficial bacterial infection model in rats (Ikai et al., 2010; Hayashi et al., 2012). In addition, in vivo studies showed that the acute locally injurious property of the disinfection technique is considerably low (Yamada et al., 2012; Sato et al., 2016). Thus, further studies should be conducted in the near future to examine if the disinfection technique with photoirradiation of GPE could be applied to the treatment of superficial infection including oral infectious diseases as describe above.

\section{AUTHOR CONTRIBUTIONS}

MaT and YN wrote the manuscript, and YN and MiT edited the manuscript. All authors approved the final version of the manuscript.

\section{ACKNOWLEDGMENTS}

This study was supported by JSPS KAKENHI Grant-in-Aid for Scientific Research (C), 17K07788, 2017, and Mext-supported program for the strategic research foundation at private universities, Japan, S1312001, 2013.

\section{REFERENCES}

Ahmad, N., Gupta, S., and Mukhtar, H. (2000). Green tea polyphenol epigallocatechin-3-gallate differentially modulates nuclear factor kappaB in cancer cells versus normal cells. Arch. Biochem. Biophys. 376, 338-346. doi: 10.1006/abbi.2000.1742

Arakawa, H., Maeda, M., Okubo, S., and Shimamura, T. (2004). Role of hydrogen peroxide in bactericidal action of catechin. Biol. Pharm. Bull. 27, 277-281. doi: $10.1248 / \mathrm{bpb} .27 .277$

Bounty, S., Rodriguez, R. A., and Linden, K. G. (2012). Inactivation of adenovirus using low-dose $\mathrm{UV} / \mathrm{H}_{2} \mathrm{O}_{2}$ advanced oxidation. Water Res. 46, 6273-6278. doi: 10.1016/j.watres.2012.08.036

Hanasaki, Y., Ogawa, S., and Fukui, S. (1994). The correlation between active oxygens scavenging and antioxidative effects of flavonoids. Free Radic. Biol. Med. 16, 845-850. doi: 10.1016/0891-5849(94)90202-X

Hayakawa, F., Kimura, T., Maeda, T., Fujita, M., Sohmiya, H., Fujii, M., et al. (1997). DNA cleavage reaction and linoleic acid peroxidation induced by tea catechins in the presence of cupric ion. Biochim. Biophys. Acta 1336, 123-131. doi: 10.1016/S0304-4165(97)00019-6

Hayashi, E., Mokudai, T., Yamada, Y., Nakamura, K., Kanno, T., Sasaki, K., et al. (2012). In vitro and in vivo anti-Staphylococcus aureus activities of a new disinfection system utilizing photolysis of hydrogen peroxide. J. Biosci. Bioeng. 114, 193-197. doi: 10.1016/j.jbiosc.2012.03.020

Heim, K. E., Tagliaferro, A. R., and Bobilya, D. J. (2002). Flavonoid antioxidants: chemistry, metabolism and structure-activity relationships. J. Nutr. Biochem. 13, 572-584. doi: 10.1016/S0955-2863(02)00208-5

Ikai, H., Nakamura, K., Shirato, M., Kanno, T., Iwasawa, A., Sasaki, K., et al. (2010). Photolysis of hydrogen peroxide, an effective disinfection system via hydroxyl radical formation. Antimicrob. Agents Chemother. 54, 5086-5091. doi: 10.1128/AAC.00751-10

Ikai, H., Odashima, Y., Kanno, T., Nakamura, K., Shirato, M., Sasaki, K., et al. (2013). In vitro evaluation of the risk of inducing bacterial resistance to disinfection treatment with photolysis of hydrogen peroxide. PLOS ONE 8:e81316. doi: 10.1371/journal.pone.0081316

Keen, O. S., Baik, S., Linden, K. G., Aga, D. S., and Love, N. G. (2012). Enhanced biodegradation of carbamazepine after $\mathrm{UV} / \mathrm{H}_{2} \mathrm{O}_{2}$ advanced oxidation. Environ. Sci. Technol. 46, 6222-6227. doi: 10.1021/es300897u

Keen, O. S., and Linden, K. G. (2013). Degradation of antibiotic activity during $\mathrm{UV} / \mathrm{H}_{2} \mathrm{O}_{2}$ advanced oxidation and photolysis in wastewater effluent. Environ. Sci. Technol. 47, 13020-13030. doi: 10.1021/es402472x

Keen, O. S., Love, N. G., Aga, D. S., and Linden, K. G. (2016). Biodegradability of iopromide products after $\mathrm{UV} / \mathrm{H}_{2} \mathrm{O}_{2}$ advanced oxidation. Chemosphere 144, 989-994. doi: 10.1016/j.chemosphere.2015.09.072

Khan, H. Y., Zubair, H., Faisal, M., Ullah, M. F., Farhan, M., Sarkar, F. H., et al. (2014). Plant polyphenol induced cell death in human cancer cells involves mobilization of intracellular copper ions and reactive oxygen species generation: a mechanism for cancer chemopreventive action. Mol. Nutr. Food Res. 58, 437-446. doi: 10.1002/mnfr.201300417

Khan, N., and Mukhtar, H. (2007). Tea polyphenols for health promotion. Life Sci. 81, 519-533. doi: 10.1016/j.lfs.2007.06.011

Kondo, K., Kurihara, M., Miyata, N., Suzuki, T., and Toyoda, M. (1999). Scavenging mechanisms of (-)-epigallocatechin gallate and (-)-epicatechin gallate on peroxyl radicals and formation of superoxide during the inhibitory action. Free Radic. Biol. Med. 27, 855-863. doi: 10.1016/S0891-5849(99)00133-1

Lafka, T., Sinanoglou, V., and Lazos, E. S. (2007). On the extraction and antioxidant activity of phenolic compounds from winery wastes. Food Chem. 104, 1206-1214. doi: 10.1016/j.foodchem.2007.01.068

Lester, Y., Aga, D. S., Love, N. G., Singh, R. R., Morrissey, I., and Linden, K. G. (2016). Integrative advanced oxidation and biofiltration for treating pharmaceuticals in wastewater. Water Environ. Res. 88, 1985-1993. doi: 10.2175/106143016X145046697 67454

Liu, Z., Ma, L. P., Zhou, B., Yang, L., and Liu, Z. L. (2000). Antioxidative effects of green tea polyphenols on free radical initiated and photosensitized peroxidation of human low density lipoprotein. Chem. Phys. Lipids 106, 53-63. doi: 10.1016/S0009-3084(00) 00133-X

Markis, D. P., Boskou, G., and Andrikopoulos, M. K. (2007). Polyphenolic content and in vitro antioxidant characteristics of wine industry and other agri-food solid waste extracts. J Food Compos. Anal. 20, 125-132. doi: 10.1016/j.jfca.2006.04.010

Nakamura, K., Ishiyama, K., Sheng, H., Ikai, H., Kanno, T., and Niwano, Y. (2015). Bactericidal activity and mechanism of photoirradiated polyphenols against gram-positive and -negative bacteria. J. Agric. Food Chem. 63, 7707-7713. doi: $10.1021 /$ jf5058588

Nakamura, K., Kanno, T., Ikai, H., Sato, E., Mokudai, T., Niwano, Y., et al. (2010). Reevaluation of quantitative ESR spin trapping analysis of hydroxyl radical by applying sonolysis of water as a model system. Bull. Chem. Soc. Jpn. 83, 1037-1046. doi: 10.1246/bcsj.20100078

Nakamura, K., Shirato, M., Ikai, H., Kanno, T., Sasaki, K., Kohno, M., et al. (2013). Photo-irradiation of proanthocyanidin as a new disinfection technique via reactive oxygen species formation. PLoS ONE 8:e60053. doi: 10.1371/journal.pone.0060053

Nakamura, K., Shirato, M., Kanno, T., Lingström, P., Örtengren, U., and Niwano, Y. (2017). Photo-irradiated caffeic acid exhibits antimicrobial activity against Streptococcus mutans biofilms via hydroxyl radical formation. Sci. Rep. 7:6353. doi: 10.1038/s41598-017-07007-z

Nakamura, K., Yamada, Y., Ikai, H., Kanno, T., Sasaki, K., and Niwano, Y. (2012). Bactericidal action of photoirradiated gallic acid via reactive oxygen species formation. J. Agric. Food Chem. 60, 10048-10054. doi: 10.1021/jf30 $3177 \mathrm{p}$

Parker, A. M., Lester, Y., Spangler, E. K., von Gunten, U., and Linden, K. G. (2017). $\mathrm{UV} / \mathrm{H}_{2} \mathrm{O}_{2}$ advanced oxidation for abatement of organophosphorous pesticides and the effects on various toxicity screening assays. Chemosphere 182, 477-482. doi: 10.1016/j.chemosphere.2017.04.150

Pryor, W. A. (1986). Oxy-radicals and related species: their formation, lifetimes, and reactions. Annu. Rev. Physiol. 48, 657-667. doi: 10.1146/annurev.ph.48.030186.003301

Roots, R., and Okada, S. (1975). Estimation of life times and diffusion distances of radicals involved in $\mathrm{x}$-ray-induced DNA strand breaks of 
killing of mammalian cells. Radiat. Res. 64, 306-320. doi: 10.2307/35 74267

Russ, W., and Meyer-Pittroff, R. (2004). Utilizing waste products from the food production and processing industries. Crit. Rev. Food Sci. Nutr. 44, 57-62. doi: 10.1080/10408690490263783

Sato, H., Niwano, Y., Nakamura, K., Mokudai, T., Ikai, H., Kanno, T., et al. (2016). Efficacy and safety of a therapeutic apparatus using hydrogen peroxide photolysis to treat dental and periodontal infectious diseases. J. Toxicol. Sci. 41, 793-799. doi: 10.2131/jts. 41.793

Tsukada, M., Nakashima, T., Kamachi, T., and Niwano, Y. (2016a). Prooxidative potential of photo-irradiated aqueous extracts of grape pomace, a recyclable resource from winemaking process. PLoS ONE 11:e0158197. doi: 10.1371 /journal.pone.0158197

Tsukada, M., Sheng, H., Kamachi, T., and Niwano, Y. (2016b). Microbicidal action of photoirradiated aqueous extracts from wine lees. J. Food Sci. Technol. 53, 3020-3027. doi: 10.1007/s13197-016-2273-1

Tsukada, M., Sheng, H., Tada, M., Mokudai, T., Oizumi, S., Kamachi, T., et al. (2016c). Bactericidal action of photo-irradiated aqueous extracts from the residue of crushed grapes from winemaking. Biocontrol Sci. 21, 113-121. doi: $10.4265 /$ bio. 21.113
Williamson, G., and Manach, C. (2005). Bioavailability and bioefficacy of polyphenols in humans. II. Review of 93 intervention studies. Am. J. Clin. Nutr. 81, 243s-255s.

Yamada, Y., Mokudai, T., Nakamura, K., Hayashi, E., Kawana, Y., Kanno, T., et al. (2012). Topical treatment of oral cavity and wounded skin with a new disinfection system utilizing photolysis of hydrogen peroxide in rats. J. Toxicol. Sci. 37, 329-335. doi: 10.2131/jts.37.329

Yilmaz, Y., and Toledo, R. T. (2004). Major flavonoids in grape seeds and skins: antioxidant capacity of catechin, epicatechin, and gallic acid. J. Agric. Food Chem. 52, 255-260. doi: 10.1021/jf030117h

Conflict of Interest Statement: The authors declare that the research was conducted in the absence of any commercial or financial relationships that could be construed as a potential conflict of interest.

Copyright (c) 2017 Niwano, Tada and Tsukada. This is an open-access article distributed under the terms of the Creative Commons Attribution License (CC BY). The use, distribution or reproduction in other forums is permitted, provided the original author(s) or licensor are credited and that the original publication in this journal is cited, in accordance with accepted academic practice. No use, distribution or reproduction is permitted which does not comply with these terms. 